\title{
Successful multiple burr hole openings for limb-shaking transient ischemic attack due to moyamoya disease: illustrative case
}

\author{
Yusuke Ikeuchi, MD, Noriaki Ashida, MD, PhD, Masamitsu Nishihara, MD, PhD, and Kohkichi Hosoda, MD, PhD \\ Department of Neurosurgery, Nishi-Kobe Medical Center, Kobe, Japan
}

BACKGROUND Limb-shaking transient ischemic attacks (LS-TIAs) are a rare form of TIAs that present as involuntary movements of the limbs and indicate severe cerebral hypoperfusion. LS-TIAs are often reported in patients with carotid artery stenosis but can also affect patients with intracranial artery stenosis and moyamoya disease (MMD).

OBSERVATIONS A 72-year-old woman presented with repeated episodes of involuntary shaking movements of the right upper limb. Cerebral angiography revealed complete occlusion of the M1 segment of the left middle cerebral artery (MCA), and the left hemisphere was supplied by moyamoya vessels. She was treated with left direct revascularization without complications, and her involuntary movements subsided. However, she demonstrated involuntary shaking movements of the right lower limb 2 months postoperatively. Cerebral angiography revealed complete occlusion of the $\mathrm{A} 1$ segment of the left anterior cerebral artery (ACA). The multiple burr hole opening (MBHO) procedure was performed to improve perfusion in the left ACA territory and after 3 months, the patient's symptoms resolved.

LESSONS This case demonstrated that LS-TIAs can also develop as ischemic symptoms due to MMD. Moreover, instances of LS-TIA of the upper and lower limbs developed separately in the same patient. The patient's symptoms improved with direct revascularization and MBHO.

https://thejns.org/doi/abs/10.3171/CASE21401

KEYWORDS limb-shaking; moyamoya disease; multiple burr hole opening

Limb-shaking transient ischemic attacks (LS-TIAs) are a rare form of TIAs that present as involuntary movements of the arms or legs or both and are often confused with focal motor seizures. ${ }^{1,2}$ This distinction is crucial because this form of TIA often indicates severe carotid occlusive disease, and patients with LS-TIAs are at high risk of future stroke. ${ }^{3,4}$ Recently, some authors have reported that anterior cerebral artery (ACA) or middle cerebral artery (MCA) stenosis or moyamoya disease (MMD) can induce LS-TIA. ${ }^{5-8}$ The pathophysiology of this syndrome has not yet been completely identified. LS-TIA is believed to be associated with the basal ganglia, the dorsolateral frontal cortex, or both in cases of cerebral hypoperfusion. ${ }^{7,9-12}$ Moreover, there have been only a few reports of LSTIA resolution via surgical revascularization procedures. ${ }^{8,13-15}$
Here, we report a case of MMD presenting with LS-TIA in the upper limb, which improved after superficial temporal artery (STA) MCA anastomosis and encephalo-duro-myo-arterio-pericranial synangiosis (EDMAPS). ${ }^{16}$ The patient subsequently developed LS-TIA in the lower limb due to ACA occlusion, which was treated using the multiple burr hole opening (MBHO) procedure. ${ }^{17}$ We believe that this is the first report of improved LS-TIAs in the upper and lower limbs after two revascularization surgeries.

\section{Illustrative Case}

History and Examination

A 72-year-old woman presented with reports of episodes of involuntary shaking movements of the right upper limb. The shaking movements were

ABBREVIATIONS ACA = anterior cerebral artery; $C E A=$ carotid endarterectomy; DSA = digital subtraction angiography; EDAS = encephalo-duro-arterio-synangiosis; EDMAPS = encephalo-duro-myo-arterio-pericranial synangiosis; LS-TIA = limb-shaking transient ischemic attacks; $\mathrm{MBHO}=$ multiple burr hole opening; $\mathrm{MCA}=$ middle cerebral artery; $M M D=$ moyamoya disease; $M R A=$ magnetic resonance angiography; $M R I=M R$ imaging; SPECT = single photon emission computed tomography; STA = superficial temporal artery; TIA = transient ischemic attack.

INCLUDE WHEN CITING Published September 6, 2021; DOI: 10.3171/CASE21401.

SUBMITTED July 8, 2021. ACCEPTED July 27, 2021.

(c) 2021 The authors, CC BY-NC-ND 4.0 (http://creativecommons.org/licenses/by-nc-nd/4.0/). 
restricted to the upper limbs, occurred at 3 to $4 \mathrm{~Hz}$, lasted for 10 seconds each, and occurred approximately once a week over the past year. The patient's consciousness was never impaired, and there were no other symptoms. Interictal electroencephalography results were unremarkable. She had a history of diabetes and anemia and no history of alcohol abuse, drug abuse, or syncope. Brain magnetic resonance imaging (MRI) revealed a small, old-appearing white matter cerebral infarction (Fig. 1A). MR angiography (MRA) and digital subtraction angiography (DSA) revealed complete occlusion of the M1 segment of the left MCA and development of moyamoya vessels on the left side of the brain (Fig. 1B). Baseline single photon emission computed tomography (SPECT) showed diffuse hemispheric hypoperfusion in the left MCA territory. After acetazolamide was administered, SPECT revealed markedly decreased left hemisphere vascular reserve capacity, including the MCA territory (Fig. 2A).

\section{Treatment and Posttreatment Course}

The patient received left STA-MCA anastomosis and EDMAPS of the left MCA territory (Fig. 1C). After the operation, she developed no new neurological deficit, and the involuntary movement of the right upper limb disappeared. In addition, MRI/MRA of the brain showed bypass patency and no new cerebral infarction.
Two months postoperatively, she developed episodes of involuntary right lower limb shaking, which lasted for 10 seconds each and occurred approximately twice a week. DSA showed complete occlusion of the A1 segment of the left ACA and good patency of the STA-MCA graft and EDMAPS (Fig. 1D and E). Baseline and postacetazolamide SPECT confirmed improved brain perfusion in the left MCA territory. However, it also revealed markedly decreased left ACA territory vascular reserve capacity (Fig. 2B). MBHO was used to improve perfusion in the left ACA territory; four burr holes were created in the left frontal region under general anesthesia (Fig. 3A).

Three months later, the patient's involuntary lower limb movements disappeared. A follow-up DSA performed 10 months after surgery revealed good blood flow through multiple burr holes to the left ACA territory (Fig. 3B-D). In addition, baseline and postacetazolamide SPECT confirmed improved perfusion of the left ACA territory (Fig. 2C).

\section{Discussion}

\section{Observations}

LS-TIA is a rare clinical feature of TIA associated with markedly impaired intracranial blood flow. ${ }^{1,2,4}$ it is characterized by brief, arrhythmic flailing or jerking arm or leg movements, which usually
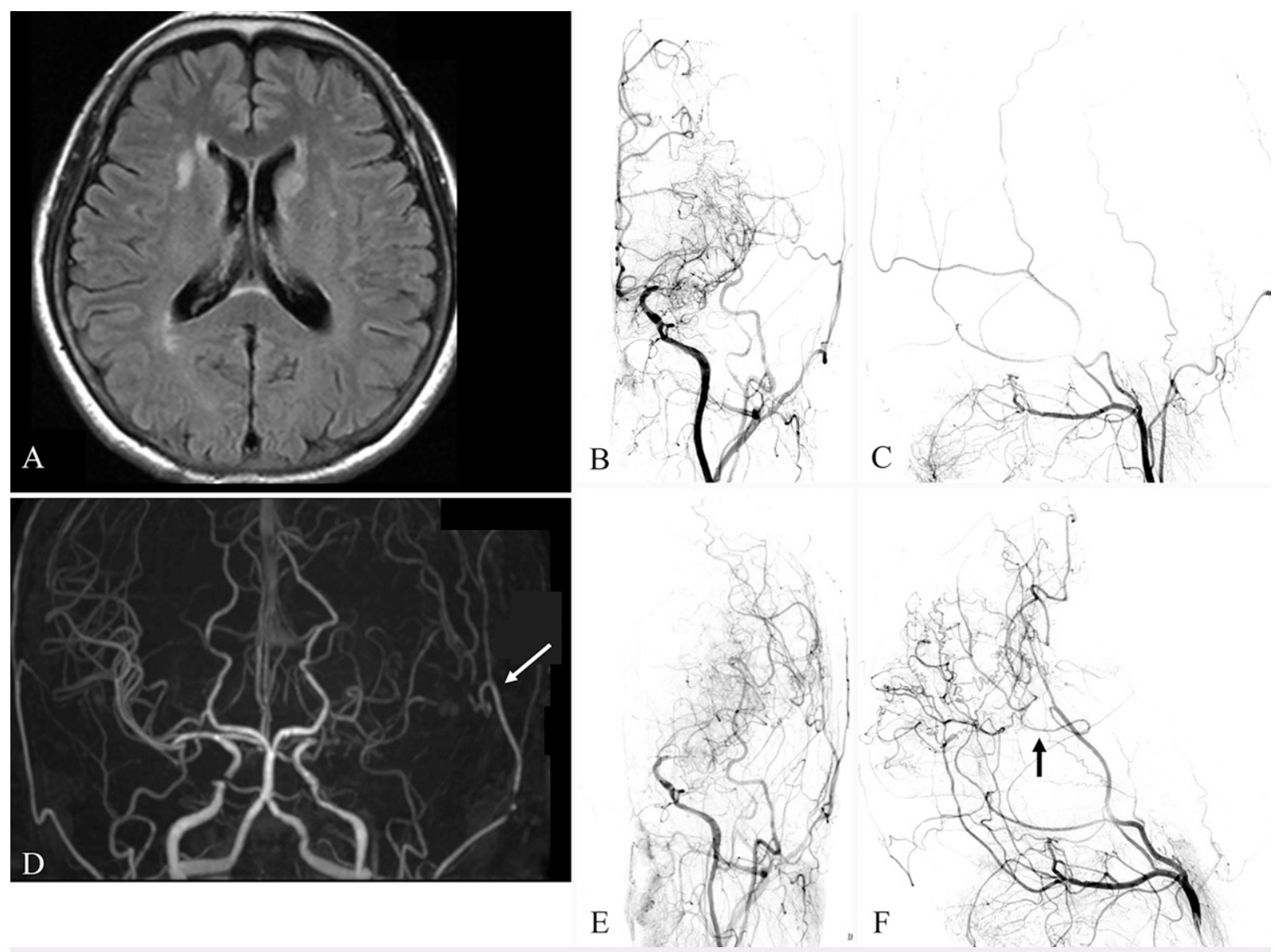

FIG. 1. A: Preoperative fluid-attenuated inversion-recovery MRI shows old infarctions in the bilateral deep white matter. B: Preoperative common carotid artery angiography (frontal view) reveals occlusion of the left M1 segment and moyamoya-like vessels. C: Preoperative external carotid artery angiography (lateral view). D: MRA shows good bypass patency (white arrow) on the next day of surgery. E: Postoperative common carotid artery angiography (frontal view) shows complete occlusion of the A1 segment of the left ACA and good patency of the STA-MCA graft and EDMAPS. F: External carotid artery angiography (lateral view) shows good patency of the STA-MCA graft (black arrow) and EDMAPS. 


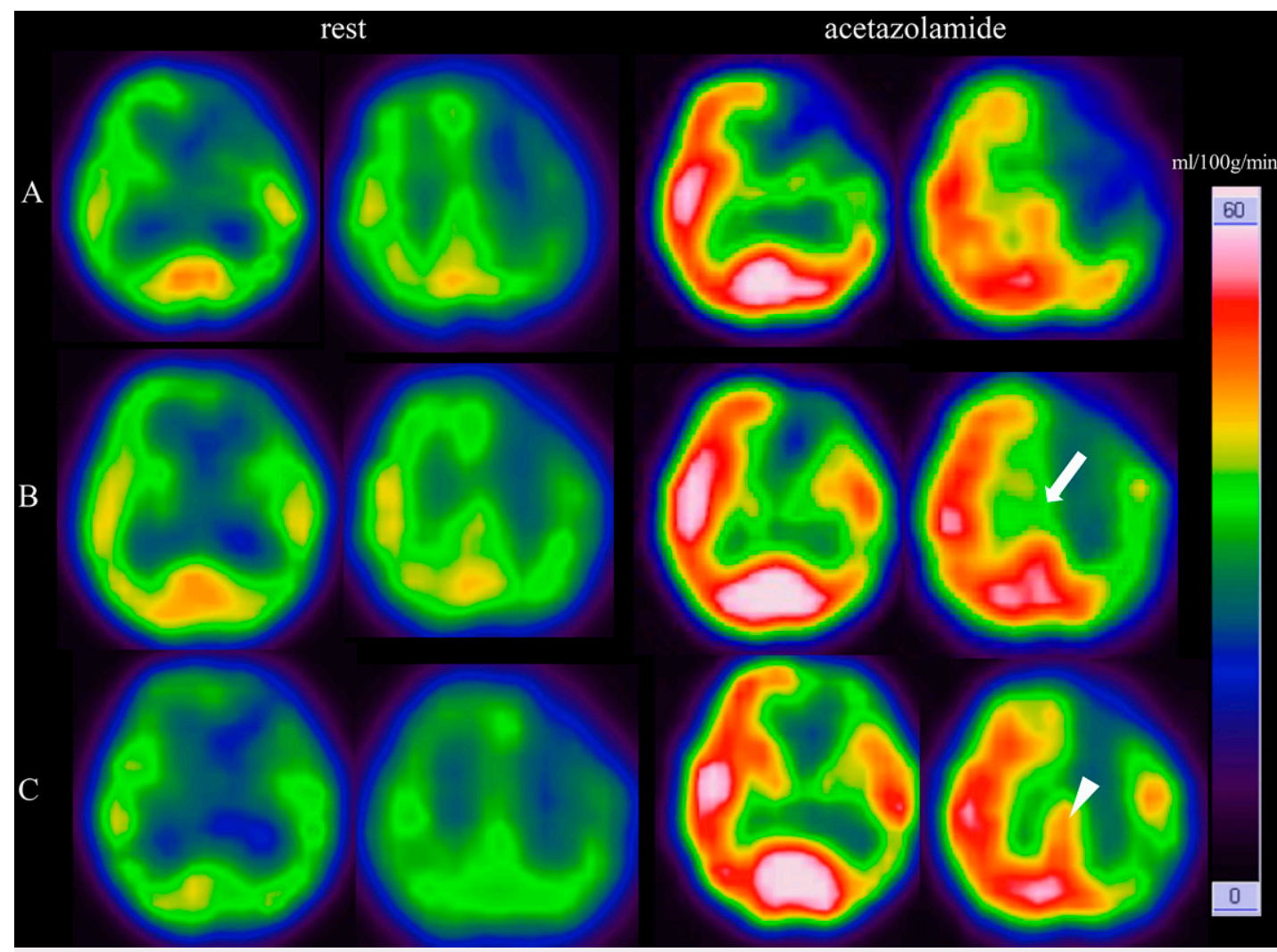

FIG. 2. SPECT before and after cerebral revascularization. A: SPECT before STA-MCA bypass and EDMAPS. B: SPECT after STA-MCA bypass and EDMAPS and before MBHO. White arrow indicates reduced cerebral vasoreactivity in the ACA territory compared with panel A. C: SPECT after MBHO. White arrowhead indicates improved cerebral vasoreactivity in the ACA territory compared with panel B. Rainbow displaying cerebral blood flow from 0 to $60 \mathrm{~mL} / 100 \mathrm{~g}$ per minute appears on the right.

have a course and a wavering character. ${ }^{4}$ Because TIAs are typically associated with negative neurological symptoms, symptomatic LS-TIA can be misdiagnosed as focal motor seizures because of its short period and recurrent incidence. ${ }^{18}$ These distinctions are crucial because LS-TIA is usually a sign of severe carotid stenosis, and patients are at high risk of future stroke. ${ }^{18}$ LS-TIAs are often reported as severe internal carotid steno-occlusive disease. However, there are also reports of other diseases associated with poor


FIG. 3. A: Sagittal view of post-MBHO. Four burr holes are pierced in the left frontal region. B and C: A follow-up DSA 10 months after MBHO revealing blood flow through multiple burr holes to the left ACA territory from both the left (B, frontal view; $\mathbf{C}$, lateral view) external carotid arteries (black arrows). No blood flow in ACA territory in Fig. 1E compared with positive blood flow in Fig. 3B. 
intracranial blood flow, such as intracranial large vessel occlusion, external carotid artery occlusion, and MMD. ${ }^{2,5-8}$ Some reports indicated that revascularization, such as carotid endarterectomy (CEA) and extracranial-intracranial anastomosis, improved LS-TIA symptoms. ${ }^{8,13-15}$

\section{Lessons}

The exact mechanism underlying limb-shaking movements is unclear. Associations of LS-TIA with the basal ganglia, the dorsolateral frontal cortex, or both have been suggested. ${ }^{7,9-12}$ Jiang et al. used ictal SPECT scans to detect predominant right cortical hypoperfusion without basal ganglia involvement. The authors suggested that the dorsolateral frontal cortex is responsible for LS-TIA. ${ }^{5}$ On the other hand, Joseph et al. reported a case in which hemiballism was improved by CEA. The authors believed that the LS-TIA was caused by subthalamic nucleus ischemia caused by the arterial border zone between perforators off the anterior choroidal artery, posterior communicating artery, and posterior cerebral artery. ${ }^{19}$ Involuntary movements are caused by disrupted balance between excitatory and inhibitory signals connecting the basal ganglia and cerebral cortex via direct and indirect pathways. ${ }^{20}$ Ischemic dysfunction of the basal ganglia, thalamus, and cerebral cortex may cause LS-TIA.

In our case, LS-TIA was first developed in the upper limbs and improved with extracranial-intracranial anastomosis of the MCA territory. Postoperative SPECT revealed improved cerebral perfusion in the MCA territory. After that, the patient developed decreased cerebral perfusion in the left ACA territory because of the left ACA occlusion, which resulted in lower-limb LS-TIA. There are two possible mechanisms for this. First, the progression of MMD may have caused ACA occlusion. According to Suzuki's vascular criteria, MMD causes narrowing of MCA and ACA in stage $11 .^{21}$ Second, the revascularization surgery for the territory of the MCA may have prompted rapid progress of carotid fork stenosis, resulting in ACA occlusion and reduction of blood flow in the ACA territory. ${ }^{22,23}$

This time, the patient's lower limb LS-TIA improved after MBHO in the left ACA territory. SPECT also indicated improvements within the ACA territory after MBHO. Because it was after EDMAPS and bypass surgery, ipsilateral direct revascularization had a risk of graft damage. For direct revascularization from the contralateral side, the length of the graft was insufficient. Uchino et al. reported that indirect bypass is effective when direct bypass is difficult in repeat bypass surgery for anterior/posterior circulation in refractory MMD. ${ }^{24}$

We reviewed the previous reports of LS-TIAs in which vascular reconstruction surgeries were performed and estimated the preand postoperative cerebral blood flow by SPECT or positron emission tomography, as in our case. The clinical characteristics and outcomes of these patients are shown in Table $1^{16,25-28}$ The eight patients (seven from previous reports plus our patient) had an age range of 8 to 84 years. The causative diseases were bilateral MMD $(n=3)$, unilateral MMD (MCA occlusion and then ACA occlusion; present case) $(n=1)$, severe MCA and ACA stenoses $(n=1)$, severe external carotid artery stenosis $(n=1)$, and severe internal cerebral artery stenosis $(n=1)$. Except for our case, acetazolamide-enhanced SPECT scans were performed before and after surgery in three cases and only before surgery in two cases, and they were missing in two cases. The surgeries included carotid endarterectomy (CEA; $n=3)$, STA-MCA bypass alone $(n=2)$, encephalo-duro-arterio-synangiosis (EDAS) only $(n=1)$, STA-MCA plus

TABLE 1. Literature review of patients with LS-TIAs who underwent vascular reconstruction

\begin{tabular}{|c|c|c|c|c|c|c|c|c|}
\hline $\begin{array}{l}\text { Authors \& } \\
\text { Year }\end{array}$ & Age & Sex & Presentation & Diagnosis & Preoperative SPECT & $\begin{array}{l}\text { Postoperative } \\
\text { SPECT }\end{array}$ & Treatment & $\begin{array}{l}\text { LS After } \\
\text { Surgery }\end{array}$ \\
\hline \multirow[t]{3}{*}{$\begin{array}{l}\text { Im et al., } \\
2004^{25}\end{array}$} & 44 & $M$ & $\begin{array}{l}\text { Lt upper \& } \\
\text { lower LS }\end{array}$ & Bilat MMD & $\begin{array}{l}\text { Hypoperfusion in rt } \\
\text { frontal regions }\end{array}$ & Improved & EDAS & Disappeared \\
\hline & 50 & M & $\begin{array}{l}\text { Lt upper \& } \\
\text { lower LS }\end{array}$ & $\begin{array}{l}\text { Severe rt MCA \& } \\
\text { ACA stenosis }\end{array}$ & $\begin{array}{l}\text { Hypoperfusion in rt } \\
\text { frontal regions }\end{array}$ & Improved & STA-MCA & Disappeared \\
\hline & 28 & $\mathrm{~F}$ & $\begin{array}{l}\text { Lt upper \& } \\
\text { lower LS }\end{array}$ & Bilat MMD & $\begin{array}{l}\text { Hypoperfusion in rt } \\
\text { frontal regions }\end{array}$ & Improved & STA-MCA & Disappeared \\
\hline \multirow[t]{2}{*}{$\begin{array}{l}\text { Morigaki et al., } \\
2006^{26}\end{array}$} & 75 & $M$ & Lt upper LS & $\begin{array}{l}\text { Severe rt ICA } \\
\text { stenosis }\end{array}$ & $\begin{array}{c}\text { Severe hypoperfusion in } \\
\text { it hemisphere }\end{array}$ & Improved & Rt CEA & Disappeared \\
\hline & 77 & $\mathrm{~F}$ & Lt lower LS & $\begin{array}{l}\text { Severe rt ICA } \\
\text { stenosis }\end{array}$ & $\begin{array}{l}\text { Severe hypoperfusion in } \\
\text { rt hemisphere, including BG }\end{array}$ & Improved & Rt CEA & Disappeared \\
\hline $\begin{array}{l}\text { Pandey et al., } \\
2010^{27}\end{array}$ & 8 & $\mathrm{~F}$ & $\begin{array}{l}\text { Rt upper \& } \\
\text { lower LS }\end{array}$ & Bilat MMD & $\begin{array}{l}\text { Lt frontal subcortical } \\
\text { hypoperfusion }\end{array}$ & Improved & $\begin{array}{c}\text { Bilat STA-MCA, } \\
\text { EDAS }\end{array}$ & Disappeared \\
\hline Present case & $72^{\dagger}$ & $\mathrm{F}$ & Rt lower LS & $\begin{array}{l}\text { Lt MMD; It ACA } \\
\text { occlusion }\end{array}$ & $\begin{array}{l}\text { Marked CVR decrease in } \\
\text { It ACA territory }\end{array}$ & Improved & $\mathrm{MBHO}$ & Disappeared \\
\hline
\end{tabular}

$\mathrm{BG}$ = basal ganglia; $\mathrm{CVR}$ = cerebrovascular reserve capacity; $\mathrm{ECA}$ = external carotid artery; ICA = internal cerebral artery.

* Before STA-MCA anastomosis and EDMAPS.

†Before MBHO. 
EDAS $(n=1)$, and STA-MCA plus EDMAPS $(n=1)$. All patients experienced complete symptom resolution, and cerebral blood flow was improved on all SPECT scans. The results of our review suggest that widespread cerebral hypoperfusion causes LS-TIA and recovery of blood flow by direct and indirect revascularization improves the symptoms.

Some reports also indicate that LS-TIAs are related to MMD, which may be treated with surgery. $7,14,27,28$ Surgery includes extracranialintracranial anastomosis or EDAS, with improved symptoms following treatment. However, there has been no report of MBHO to treat LSTIA related to MMD. MBHO, which involves multiple burr holes and opening of the dura mater in an area of reduced cerebral blood flow, was previously described by Kawaguchi et al. ${ }^{17}$ Angiogenesis occurs early after surgery. However, blood flow from angiogenesis, which can alleviate the symptoms, is highly individualized. Because our patient was 72 years old, it may have taken 3 months for her symptoms to disappear. Eventually, however, MBHO increased cerebral blood flow and improved our patient's symptoms.

This case is rare and important for the following three reasons. First, LS-TIA of the upper and lower limbs developed separately in the same patient. Second, SPECT was used to evaluate cerebral blood flow before and after surgery. Our SPECT findings corresponded with improved symptoms and blood flow after surgery. Third, MBHO was an effective means of indirect revascularization for LS-TIA in a patient with MMD.

\section{References}

1. Fisher $\mathrm{CM}$. Concerning recurrent transient cerebral ischemic attacks. Can Med Assoc J. 1962;86:1091-1099.

2. Yanagihara T, Piepgras DG, Klass DW. Repetitive involuntary movement associated with episodic cerebral ischemia. Ann Neurol. 1985;18(2):244-250.

3. Kim JS. Symptoms of transient ischemic attack. Front Neurol Neurosci. 2014;33:82-102.

4. Das A, Baheti NN. Limb-shaking transient ischemic attack. J Neurosci Rural Pract. 2013;4(1):55-56.

5. Jiang WJ, Gao F, Du B, Srivastava T, Wang YJ. Limb-shaking transient ischemic attack induced by middle cerebral artery stenosis. Cerebrovasc Dis. 2006;21(5-6):421-422.

6. Han SW, Kim SH, Kim JK, Park CH, Yun MJ, Heo JH. Hemodynamic changes in limb shaking TIA associated with anterior cerebral artery stenosis. Neurology. 2004;63(8):1519-1521.

7. Kim HY, Chung CS, Lee J, Han DH, Lee KH. Hyperventilationinduced limb shaking TIA in Moyamoya disease. Neurology. 2003;60(1):137-139.

8. Kraemer M, Diehl RR, Diesner F, Berlit P, Khan N. Differential diagnosis between cerebral ischemia, focal seizures and limb shaking TIAs in moyamoya disease. Br J Neurosurg. 2012;26(6):896-898.

9. Zaidat OO, Werz MA, Landis DM, Selman W. Orthostatic limb shaking from carotid hypoperfusion. Neurology. 1999;53(3):650-651.

10. Tatemichi TK, Young WL, Prohovnik I, Gitelman DR, Correll JW, Mohr JP. Perfusion insufficiency in limb-shaking transient ischemic attacks. Stroke. 1990;21(2):341-347.

11. Ghika-Schmid F, Ghika J, Regli F, Bogousslavsky J. Hyperkinetic movement disorders during and after acute stroke: the Lausanne Stroke Registry. J Neurol Sci. 1997;146(2):109-116.

12. Shimizu T, Hiroki M, Yamaoka Y, et al. Alternating paroxysmal hemiballism-hemichorea in bilateral internal carotid artery stenosis. Intern Med. 2001;40(8):808-812.

13. Kalia J, Wolfe T, Zaidat OO. Limb-shaking transient ischemic attack masquerading as lumbar radiculopathy from pericallosal artery stenosis treated successfully with intracranial angioplasty and stenting. J Stroke Cerebrovasc Dis. 2010;19(2):169-173.

14. Khan S, Chang E, Saniuk G, Shang T. Bilateral asymmetrical asterixis as limb-shaking transient ischemic attack in bilateral carotid stenosis. J Stroke Cerebrovasc Dis. 2015;24(1):e29-e30.

15. Bund $C$, Heimburger $C$, Wolff $V$, Namer IJ. Positional brain singlephoton emission computed tomography findings in a case of limbshaking syndrome. J Stroke Cerebrovasc Dis. 2018;27(5): 1420-1422.

16. Kuroda S, Houkin K, Ishikawa T, Nakayama N, Iwasaki Y. Novel bypass surgery for moyamoya disease using pericranial flap: its impacts on cerebral hemodynamics and long-term outcome. Neurosurgery. 2010;66(6):1093-1101.

17. Kawaguchi T, Fujita S, Hosoda K, et al. Multiple burr-hole operation for adult moyamoya disease. J Neurosurg. 1996;84(3):468-476.

18. Ali S, Khan MA, Khealani B. Limb-shaking transient ischemic attacks: case report and review of literature. BMC Neurol. 2006;6:5.

19. Joseph JR, Delavari N, Wilkinson DA, et al. A case of complete resolution of hemiballismus after carotid endarterectomy. World Neurosurg. 2016;95:620-624.

20. Alexander GE, Crutcher MD. Functional architecture of basal ganglia circuits: neural substrates of parallel processing. Trends Neurosci. 1990;13(7):266-271.

21. Suzuki J, Kodama N. Moyamoya disease: a review. Stroke. 1983;14(1):104-109.

22. Iwama T, Hashimoto N, Miyake H, Yonekawa Y. Direct revascularization to the anterior cerebral artery territory in patients with moyamoya disease: report of five cases. Neurosurgery. 1998;42(5):1157-1162.

23. Kuroda S, Houkin K, Nunomura M, Abe H. Frontal lobe infarction due to hemodynamic change after surgical revascularization in moyamoya disease: two case reports. Neurol Med Chir (Tokyo). 2000;40(6):315-320.

24. Uchino H, Kashiwazaki D, Akioka N, et al. Strategy and effect of repeat bypass surgery for anterior/posterior circulation in refractory moyamoya disease. J Neurosurg. 2019;132(6):1889-1899.

25. Im SH, Oh CW, Kwon OK, Cho BK, Chung YS, Han DH. Involuntary movement induced by cerebral ischemia: pathogenesis and surgical outcome. J Neurosurg. 2004;100(5):877-882.

26. Morigaki R, Uno M, Suzue A, Nagahiro S. Hemichorea due to hemodynamic ischemia associated with extracranial carotid artery stenosis. Report of two cases. J Neurosurg. 2006;105(1):142-147.

27. Pandey P, Bell-Stephens T, Steinberg GK. Patients with moyamoya disease presenting with movement disorder. Report of 4 cases. J Neurosurg Pediatr. 2010;6(6):559-566.

28. Ho SC, Lin HJ, Tsui YK, Yeh PS. Limb-shaking TIA related to moyamoya disease: diagnosis with magnetic resonance imaging and magnetic resonance angiography. Acta Neurol Taiwan. 2010;19(4):270-274.

\section{Disclosures}

The authors report no conflict of interest concerning the materials or methods used in this study or the findings specified in this paper.

\section{Author Contributions}

Conception and design: Ikeuchi, Ashida, Hosoda. Acquisition of data: Ikeuchi, Hosoda. Analysis and interpretation of data: Ikeuchi, Hosoda. Drafting the article: Ikeuchi. Critically revising the article: Ikeuchi, Nishihara, Hosoda. Reviewed submitted version of manuscript: Ikeuchi, Hosoda. Approved the final version of the manuscript on behalf of all authors: Ikeuchi. Administrative/technical/material support: Ikeuchi, Nishihara, Hosoda. Study supervision: Ikeuchi, Hosoda.

\section{Correspondence}

Yusuke Ikeuchi: Nishi-Kobe Medical Center, Kobe, Japan. ikesuke35@ yahoo.co.jp. 